\title{
Author Correction: Protective role of the Arabidopsis leaf microbiota against a bacterial pathogen
}

Christine M. Vogel, Daniel B. Potthoff, Martin Schäfer, Niculò Barandun and Julia A. Vorholt (i)

Correction to: Nature Microbiology https://doi.org/10.1038/s41564-021-00997-7, published online 24 November 2021.

In the version of this Article originally published, there was an error in Supplementary Fig. 5. By mistake the 16 dpi panel for Xanthomonas Leaf131 showed the 16 dpi image of Xanthomonas Leaf148. This error has now been corrected and the updated Supplementary Information File is available online.

Published online: 6 January 2022

https://doi.org/10.1038/s41564-022-01058-3

(c) The Author(s), under exclusive licence to Springer Nature Limited 2022 